\title{
Contratempos e sobressaltos: os eclipses como fenômenos da natureza humana
}

\author{
RENATA SieIRo FERNANDES
}

Pedagoga, mestre e doutoranda em Ciências Sociais aplicadas à Educação pela Unicamp

\section{RESUMO}

Este artigo mostra alguns desafios metodológicos que surgem no decorrer de uma pesquisa e a busca por novos caminhos. Fala de atos políticos que arruinam o espaço de um projeto educativo do tipo não-formal e provocam sentimentos fortes em seus freqüentadores e educadores. Isso inaugura um novo período em que a memória serve como base para as ressignificações tanto do espaço arquitetônico como do próprio processo educacional.

Palavras-chave: Projetos educacionais. Educação não-formal. Políticas públicas

\section{Abstract}

This article presents some methodological challenges which emerge during a research development, as well as the search for new directions.

It tells us about political actions that lead a Non Formal Education Project to collapse and the range of emotions which arise into educators and partakers as a consequence. The mentioned events inaugurate a new period in which memory serves to the people envolved as basis to re-significance of both: architectonic space and educational process.

Key words: Education projects. Non formal education. Publics policies 
Arena e salas de atividades

identificadas por cores difierentes

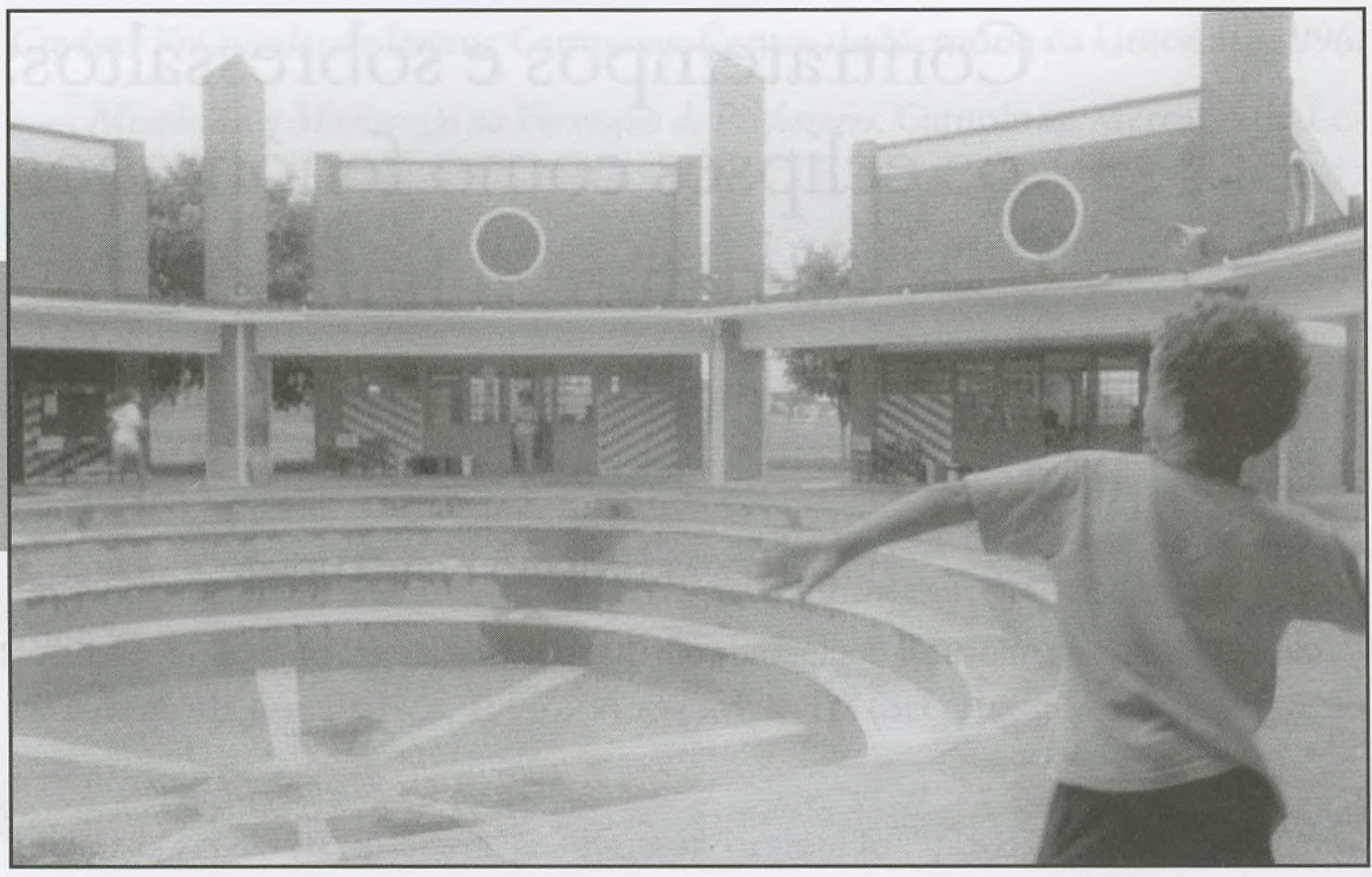

"A vida estrondeia e pulveriza a alma

mas a arte relembra que você tem uma"

(Stella Adler)

1 - Este artigo faz parte do meu texto de doutorado ainda em andamento.

\section{2 - Para um} aprofundamento na discussão da educação não-formal, ver Simson, Parke Fernandes, Educação Não-formal: Cenários da Criação, 2001.

\section{3 - Esse Programa} acontecia nas dependências do Projeto Sol, utilizando de sua estrutura arquitetônica.

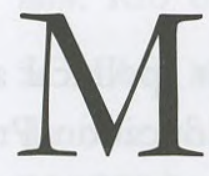

eados de 2000. Ano de grandes mudanças que não se anunciavam. Tempo de redefinições, remanejamentos, reorientações externas e internas. Momentos de crises que trouxeram à tona os conflitos e estimularam reelaborações internas. Rupturas que levaram embora o já enraigado e que abriram espaço para novas possibilidades. Tempo de reconstrução, de juntar os cacos e de procurar uni-los ou aproximá-los na tentativa de tecer sentidos e novos significados que possam vir a ser alavancas para novas buscas e novos projetos.

No decorrer do desenvolvimento de uma pesquisa de Doutorado [1], na área de Ciências Sociais Aplicadas à Educação, iniciada no ano de 2000, uma situação atingiu-nos de surpresa. Apesar do sucesso e dos efeitos positivos que um projeto de educação não-formal [2] para crianças e jovens (de 7 a 14 anos) oriundos de classes de baixo nível sócio-econômico, vinha conseguindo ao longo dos anos, chamado de Projeto Sol - locus de tal pesquisa -, bem como um projeto com as mesmas orientações mas destinado a um público de maior faixa etária (a partir dos 15 anos), chamado de Programa Noite Viva [3], a atual gestão administrativa da prefeitura da cidade de Paulínia extinguiu-os, 
realocando seus funcionários - à revelia desses - para outras funções e lugares e deixando seu público frequentador à mercê das intempéries que assolam o universo das ações políticas. E, por enquanto, não foi oferecido nada parecido e não apareceram propostas novas para atender a essa população de crianças, jovens e adultos, que agora volta a passar grande parte de seu tempo em casa ou na rua.

O espaço do Projeto Sol continua lá - sua construção arquitetônica entretanto, re-significado, reformado para atender a um público de menor idade, de educação infantil. Transforma-se, agora, em escola. O espaço circular, radial, solar, aberto, que foi pensado, planejado e construído com determinada e particular finalidade será re-ocupado e terá nova função. Isso, a princípio, não é negativo. Entretanto, se pensarmos que a realidade da educação formal é, quase sempre, aproveitar- se e adequar- se ao que já existe e está disponível, inclusive aos espaços arquitetônicos, isso implica em um descuido com a sua qualidade e real importância.

Paralelamente a isso, indica, mais uma vez, a dificuldade que a educação formal tem de repensar sua rigidez e procurar flexibilizar o seu funcionamento e estrutura convencionais, pois mesmo tomando posse da construção "solar" do Projeto, sua preocupação maior - depois de repintá-lo, mobiliá-lo e adaptálo ao tamanho das crianças e aos objetivos da educação formal - foi, decididamente, soterrar a arena circular e central da edificação, transfigurandoa em jardim. Um jardim existe para ser olhado, apreciado; uma arena existe para ser ocupada, vivenciada.

Gaston BACHELARD (s/d) fala sobre a poética dos espaços quando se propõe a interpretar os símbolos que os compõem, usando-se de pensamentos filosóficos e psicológicos que embasam seus devaneios. E assim ele se propõe a analisar o sótão, o porão, os cantos, a espiral, a concha, etc.

$\mathrm{O}$ pintor e arquiteto vienense Hundertwasser, conhecido como "o pintor das cinco peles" também utiliza o termo "a poética" quando fala sobre a aplicação da arte, seus efeitos e influências sobre o indivíduo, seu espaço habitável, seu meio social mais imediato e mais amplo. Ambos trabalham com imagens que se desdobram em conceitos.

Os pontos-chave do ideário filosófico de Hunderwasser são: a arte, a arquitetura e o ambiente que servem como o meio para o melhor viver dos seres humanos a partir de suas cinco peles: a epiderme natural, o vestuário ou a roupa, a casa, o meio social e a identidade (a família, os amigos e a nação) e, o meio global e a ecologia e a humanidade (a esfera planetária).

Ele apostava nos três pontos-chave como forma de interferir e 
influenciar as relações dos indivíduos nos espaços de convivência - no caso da terceira, quarta e quinta peles -, acreditando, inclusive, na capacidade curativa que tais ambientes poderiam conter e potencializar.

Diz RESTANY (1999:45) acerca das pinturas e construções poéticas de Hundertwasser:

“... a especulação sobre o poder da arte tem a característica de uma aposta sobre a poética do espaço habitado. (...) É fácil encontrar na pintura de Hundertwasser imagens que prefiguram as estruturas e os pormenores das suas casas: alinhamentos irregulares de janelas, integração espacial de árvores, a mistura colorida e as linhas ondulantes dos seus planos urbanísticos, as cúpulas bulbosas e as colunadas barrocas".

Portanto, as cores, as curvas, os vãos, as abóbadas, a incidência de luzes e a projeção das sombras, os cheios e os vazios, suas presenças ou ausências, suas composições, as interações que proporcionam ou não, ajudam a constituir e a dar consistência à dimensão poética dos espaços.

No caso deste artigo, as duas imagens mais marcantes e que se sobressaem são: a arena e o jardim, ou melhor, a transformação daquela nesta, no espaço do Projeto Sol.

A imagem do jardim é muito boa e agradável mas a da arena é muito mais significativa. No Projeto Sol ela sempre foi utilizada como ponto de encontro dos frequentadores e como campo de reunião e discussão de idéias, desejos, interesses, necessidades, apresentação de notícias e novidades do diaa-dia, internas e externas ao espaço do Sol. Era o local dos debates coletivos e planejamentos das atividades diárias, antes dos grupos dirigirem-se às salas de atividade. Era onde aconteciam as apresentações artísticas, fruto do trabalho que era desenvolvido lá dentro e de espetáculos convidados. Era onde todos se encontravam, crianças, jovens e adultos. Era o picadeiro do circo, o palco do teatro, a passarela dos desfiles, a "quadra" dos jogos, o espaço de ensaio dos grupos de música. Funcionava como a ágora grega, a praça na qual as assembléias do povo e o mercado aconteciam.

Para destruir a proposta era necessário atacá-la no seu âmago, no seu ponto mais vivo, no seu "coração", justamente a arena. E foi ela o primeiro elemento a sofrer a descaracterização.

A imagem da ágora e seu significado permitem que, a princípio, se 
extrapole a idéia para se ressaltar uma hipótese - que será apenas lançada, sem maiores aprofundamentos -: a de que a escola, ou a educação formal, nos moldes em que ainda se encontra, sofre de "agorafobia", que traduz-se por "medo mórbido e angustiante de lugares públicos e grandes espaços descobertos" (dicionário AURÉLIO, 1988)

O Projeto Sol ainda existe porque persiste nos seus materiais, na pedra, no cimento, no tijolo, no cascalho utilizados para edificá-lo. Ele persiste no seu suporte arquitetônico. Como diz VIRILIO (s/d), [4] "a arquitetura não foi feita para edificar a instantaneidade. Ela foi feita para a longa duração". E ele continua,

“a arquitetura tradicional está ligada ao tempo longo. (...) a arquitetura tradicional é a pedra, é a durabilidade. Isto quer dizer que o que se constrói é construído de uma vez por todas. Toda a arquitetura tradicional, inclusive a arquitetura contemporânea do cimento armado, e até a arquitetura metálica, fundamenta-se na ideologia do tempo longo como tempo forte da estética arquitetural".

Entretanto, ao mesmo tempo em que o Sol está lá, visível, sua essência construída até o início de 2000, desapareceu, foi fragmentada, dispersada. O sentido da construção não está nela e sim no uso que se faz dela e nas relações sociais engendradas nela e por ela.

Mas, contra qualquer pessimismo precipitado, Paul VIRILIO mostra seu pensamento:
"é evidente que as coisas existem na medida em que elas não estão mais presentes, na medida em que elas desaparecem. Seu potencial de emoção está ligado ao desaparecimento. Não está mais ligado ao aparecimento. O desaparecimento suplanta o aparecimento".

Paul VIRILIO fala de uma persistência mental, espiritual, cognitiva, a que ele chama "retiniana", e que suplanta a persistência da matéria. Para ele, esse é o papel da memória pois ele a entende em uma relação com o esquecimento: "não há memória sem esquecimento, é o esquecimento que constitui a memória. (...) em outras palavras, o esquecimento não se opõe à memória, mas a realiza".
4 - Extraído de uma entrevista dada por Paul Virilio, s/d, mimeografado. 
A memória não é uma caixa forte e a qualidade dela refere-se ao trabalho do esquecimento, àquilo que se perde, que não fica retido.

Dessa forma, o Sol continua ressoando nas memórias pessoais e coletivas daqueles que puderam tomar contato mais próximo com a sua realidade. Mas o sentimento de perda é enorme e provocou abalos emocionais em muitas crianças, jovens e adultos.

Em um dos núcleos do Projeto Sol (João Aranha), a diretora exteriorizou esse sentimento através da concretização de uma cena ritualizada na qual deposita objetos, pensamentos, sentimentos e lembranças na arena que estava prestes a ser soterrada e cimentada.

O depoimento dela (feito por escrito) expressa o inestimável valor do Sol e explica a necessidade da ritualização como forma de tentativa de sublimação do sentimento negativo:

"Arena entulhada.

$\mathrm{O}$ buraco que virou arena que virou aterro como um enterro, um cemitério onde foram enterrados seus momentos.

Andar pelo aterro cimentado é como pisar nas lápides, tumbas - covas dos cemitérios; mas não parece que a gente pisa nas pessoas vivas.

Por ali ficavam as pessoas nas rodas de conversa, nas apresentações coletivas, nos teatros, nas pantomimas, acontecia ali o jogo "derruba lata".

É muito aflitiva a sensação.

O buraco virando aterro

Pegar a cadeira, sentar, cruzar as pernas - balançar os pés, braços e mãos em posição de "sócrates" e observar, assistir ao fim do Sol.

O Sol não vai mais nascer - não terão manhãs de Sol.

A morte, o definhamento, a implosão.

A cada dia ver destroços, entulhos serem jogados como se fosse buraco (assim muitas pessoas de fora do Sol chamavam a arena), como se fosse a fossa para ser aterrada.

Tudo ali foi jogado e aterrado, inclusive sonhos, esperanças, revolta, símbolos e significados, representados pela camiseta do Sol, o tênis do professor e a escrita original de um jovem participante do Projeto Sol onde ele escreveu o que significava o Sol para ele.

Onde, cadê o povo que não veio para o enterro?" 
Essa mesma diretora me forneceu uma cópia da carta escrita por um ex-frequentador, o Joab, de 15 anos, que foi elaborada especialmente para o dia do "enterro" da arena. Essa carta, datada de 3 de abril de 2001, repete a mesma paixão pelo Sol encontrada em todos os outros depoimentos de exfrequentadores e dos profissionais que lá trabalharam. Ela inicia-se assim: [5] "Projeto Sol um lugar para brincar para se divertir um lugarpara amar. Projeto Sol que pra uns era motivo de raiva pra outros era motivo de alegria, um lugarpara adquirir mais conhecimento, aprender algo que poderá um dia ajudá-lo para você ganhar a vida".

Em uma primeira referência o Sol é um lugar para brincar. Em segundo, um lugar para se divertir. Em terceiro, um lugar para amar e, em quarto, um lugar para aprender para a vida e para o trabalho.

O outro ponto de referência é a ambivalência

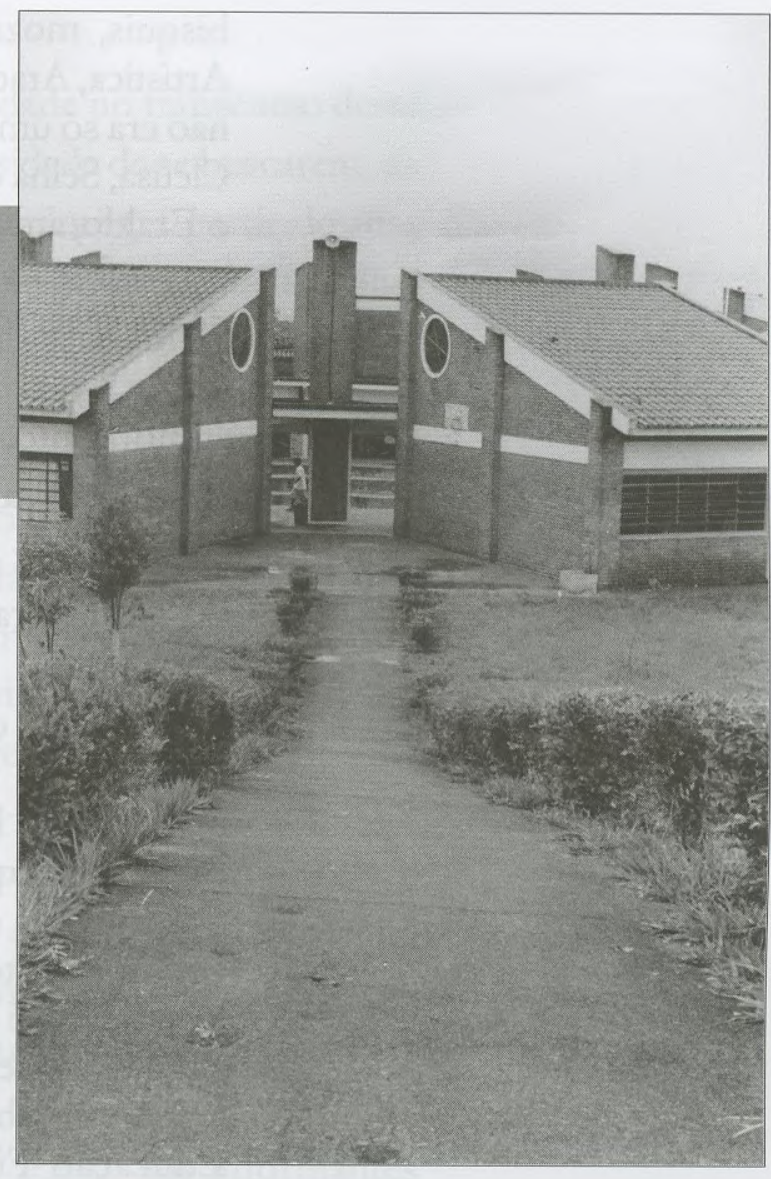
de sentimentos provocada pelo Sol: raiva pra uns (e, talvez inveja [6] também) e alegria pra outros. Os sujeitos referidos estão indeterminados mas podem ser supostos em virtude de algumas dicas que esses jovens dão: alguns dos que não aceitaram o convite do Sol para serem frequentadores? Alguns professores da escola formal? Alguns políticos insensíveis as causas sociais?

Talvez esses últimos sejam os sujeitos mais diretamente atacados em razão, inclusive, de umas linhas escritas mais abaixo na carta: "mais como todos dizerm novo milênio nova era novo século". Ele vê pistas, no seu microuniverso, de uma determinada configuração política e econômica que já está delineada no macro-universo.

Como um quinto ponto, aparecem, mencionadas, as pessoas envolvidas na dinâmica diária do Projeto, desde os "professores e professoras", passando pelas faxineiras, cozinheiras e diretores e diretoras. As referências carinhosas vão em dois sentidos: do profissional e do pessoal. Todos esses são nomeados:

5 - $A$ reprodução do texto mantém as características do original.

6 - O dicionário Aurélio define da seguinte maneira 0 termo "inveja": desgosto ou pesar pelo bem ou pela felicidade de outrem. Desejo violento de possuir o bem alheio.

"As coisas que existiam para a gente fazer e os professores (Elenise, trabalho com sucata, Lílian, 
bisquis, mozaico, Educação Física, Luiza, marcenaria, Artística, Araci, artesanato), as fachineiras, cozinheiras, que não era só uma fachineira, ou cozinheira para nós, (a Diná, Cleusa, Selha e Evanilda) e os diretores de antes e de agora, o Eraldo, amigo e diretor, Teca, amiga, irmã, mãe, diretora ou professora. Todos tinham uma profissão uma tarefa um dever, mais todos eram felizes..."

Um último ponto, bastante interessante, relaciona o espaço do Sol com o lugar idealizado do lar (o abrigo, o aconchego, o conforto, a segurança, a proteção) que pode ser associado à idéia de ninho, como pensa Bachelard.

A carta, na íntegra, sem desmembrações e recortes, é a seguinte:

"Paulínia, 3 de abril de 2001

Projeto Sol um lugar para brincar um lugar para se divertir um lugar para amar.

Projeto Sol que pra uns era motivo de raiva pra outros era motivo de alegria um lugar para adquirir mais conhecimento, aprender algo que poderá um dia ajudálo para você ganhar a vida.

As coisas que existiam para a gente fazer e os professores (Elenise, trabalho com sucata, Lílian, bisquis, mozaico, Educação Física, Luiza, marcenaria, Artística, Araci, artesanato), as fachineiras, cozinheiras, que não era só uma fachineira ou cozinheira pra nós (a Diná, Cleusa, Selha e Evanilda), e os diretores de antes e de agora (o Eraldo, amigo e diretor, Teca, amiga, irmã, mãe, diretora ou professora). Todos tinham uma profissão uma tarefa um dever, mais todos eram felizes, nesse espaço que pra mim era mais que um lugar para ficar era como uma casa, um lar, um lugar para amar.

Mais como todos dizem novo milênio nova era novo século, agora o que todos devíamos fazer é lembrar dos momentos que passamos juntos, sejam eles bons ou ruins.

E como dizem, na vida uns ganhão outros perdem, e nós perdemos o nosso bem mais querido, o nosso bem mais precioso, o Projeto SOL - João Aranha, hoje em memória, de todos e de mim".

Nesta atual situação, a memória é igual a tesouro, que será enterrado e se tornará conhecido quando vier novamente à tona, permitindo que a história seja revista, recontada e resignificada por muitos, em outros 
momentos.

Ao invés desse imprevisto provocar uma inviabilidade no transcurso desta pesquisa, reforçou ainda mais o interesse inicial e a necessidade de se buscarem as marcas e os efeitos do Sol na vida de seus ex-frequentadores, a partir de suas memórias e de suas falas, pois esta história ainda não se encontra escrita. Desde o princípio, o que motivou a construção da intenção da pesquisa foi o retorno que os ex-frequentadores forneciam para as educadoras e que passava, principalmente, por dois aspectos: o afetivo (as visitas constantes e as matrículas dos filhos dos frequentadores atestam a sua importância) e o pessoal-social (uma inserção positiva no social a partir da negação do universo da marginalidade, proporcionada pela ocupação do tempo e da "cabeça" dessas crianças e jovens frequentadores do Projeto Sol, que atesta a validade dessa iniciativa educativa).

Pelo lado deles, há, agora, mais uma razão - forte - para falarem de seus sentimentos e vivências nesse espaço já que ele encontra-se ressignificado e que a história do Sol - as partes e as versões - está com cada um que passou por ele, e pode ser conhecida e reapresentada (no sentido de trazer de novo para o presente) através de seus depoimentos e narrativas e não apenas na memória mantida sob outros suportes, como: fotografias, vídeos, álbuns, pinturas, colagens, desenhos, fantasias, textos, etc.

Entretanto, provocou uma maior dificuldade de acesso aos informantes pois os intermediários para os encontros sempre foram as educadoras, que estão, atualmente, espalhadas pela rede municipal de ensino, longe dos bairros em que se localizavam os Projetos e com menor contato com aquelas crianças e jovens que os frequentavam. Esses também, por não contarem com nenhum outro local regular de agregação que facilite o encontro, ficam mais difíceis de serem localizados e acessados. Anteriormente, o espaço do Sol servia como congregador; era lá que os encontros e as entrevistas eram feitos, pois era o local referência para todos nós (educadoras/es, frequentadores, pesquisadora).

Acredito que esse fato novo, que veio interferir na vida de todos os envolvidos no cotidiano do Sol, influenciará também os modos de referiremse a ele, ou seja, os ecos dessa situação atual poderão ser encontrados no discurso desses informantes que serão contatados daqui para frente. Acredito que essa ruptura na existência do Sol provocará os depoentes de uma maneira diferente, pois agora não podem mais contar com as visitas que faziam a ele e tampouco como um espaço educativo não-formal para seus descendentes.

$\mathrm{Na}$ terceira semana do mês de agosto de 2001, foram inauguradas, entre 
outras obras da prefeitura, as EMEI'S (Escola Municipal de Educação Infantil) que passaram a funcionar no lugar do Projeto Sol. O lugar que ficou ocioso por algum tempo, que recebeu reforma e uma nova orientação, passou a receber seu novo público e a funcionar como ensino formal e regular para crianças pequenas.

Em um conto-romance escrito por Michael ENDE (1995), o autor descreve o local onde ocorre grande parte dos acontecimentos principais da história que narra. E por coincidência, o local escolhido são as ruínas de um anfiteatro grego onde mora uma garota que não tem pais e que cuida de si com a ajuda de alguns adultos vizinhos. Essa garota chama-se Momo.

Assim é descrito esse lugar, muito semelhante ao Projeto Sol:

"Há muito, muito tempo, quando os homens ainda falavam línguas muito diferentes das nossas, nos países quentes já existiam cidades grandes e magníficas. Nelas erguiam-se palácios de reis e imperadores, havia largas avenidas, ruelas e becos estreitos, templos suntuosos com estátuas de ouro e mármore, feiras nas quais se encontravam à venda mercadorias de todos os reinos, praças bonitas e espaçosas onde o povo se reunia para discutir as últimas notícias, ouvir ou fazer discursos. E nessas cidades havia, sobretudo, grandes teatros.

Pareciam os circos de hoje, só que eram feitos de blocos de pedra. As fileiras de assentos para o público eram construídas uma acima da outra, como degraus de uma escada, formando uma espécie de imenso funil. Vistas de cima, algumas dessas construções eram circulares, outras eram mais ovais e outras, ainda, tinham a forma de um amplo semicírculo. Eram chamadas de anfiteatros" (p. 3).

Era nesse lugar que os adultos iam encontrar Momo para conversar, serem ouvidos, tentarem resolver seus problemas. Era nesse lugar que as crianças iam se reunir para ter idéias, imaginar e criar coisas novas e fantásticas, brincar com Momo.

Nesse lugar, as pessoas que lá iam "habitavam no tempo". No dizer de Paul VIRILIO (op. cit.),

"habitar no tempo é habitar sua intensidade. Por exemplo, quando estamos preocupados por causa de uma pessoa, numa palavra, quando estamos 


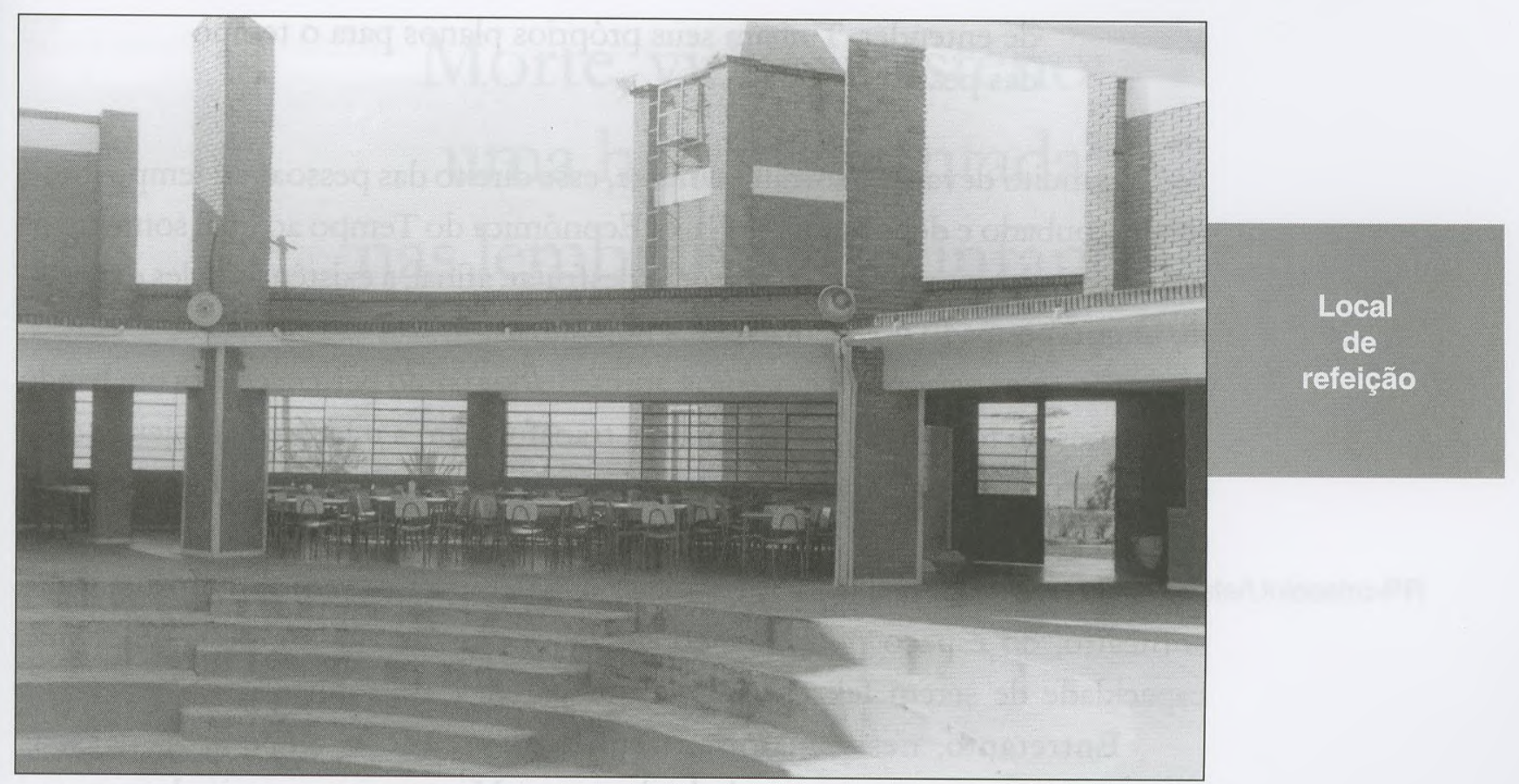

apaixonados, o tempo - assim que estamos em companhia dessa pessoa -, o tempo não passa. O tempo é um tempo intensivo, o das paixões e o da emoção. (...) mas quando se olha para o relógio, passaram-se horas. Passaram-se horas porque se investiu nesta fração de tempo uma potência emocional que dilatou o tempo. Penso que é isso habitar no tempo. É estar preocupado. Mas preocupado no bom sentido da palavra, não no sentido de uma inquietação, no sentido de que o tempo é produzido por nossas paixões".

E complementando, diz o autor sobre o tempo: “... o tempo é plástico, é uma matéria prima que nós temos que moldar, que não é um dado primeiro". Tanto as pessoas do conto de ENDE (op. cit.) quanto as pessoas do Sol, tiveram a oportunidade, enquanto esses lugares duraram, de "habitar no tempo".

Em um determinado momento do enredo do livro, aparecem uns sinistros homens cinzentos que conspiram contra essa qualidade de tempo das pessoas e que agem conjuntamente para roubá-lo.

"Tempo é vida. E a vida mora no coração. Ninguém sabia disso melhor que os homens cinzentos. (...) Claro que eles tinham sua própria maneira de entender o tempo (...). E eles agiam de acordo com essa maneira 
de entender. Tinham seus próprios planos para o tempo das pessoas" (p. 53).

E muito devagar e sorrateiramente, esse direito das pessoas ao tempo lhes é tirado, roubado e depositado na Caixa Econômica do Tempo ao qual somente os homens cinzentos têm acesso e podem desfrutar, afinal, a existência deles depende do tempo poupado dos demais seres humanos.

São esses os homens cinzentos, apresentados como pertencentes a um bando de ladrões do tempo que, ao roubarem, transformam a relação dos sujeitos com o tempo, ou seja, impedem a ação desses sujeitos sobre o tempo que passará a ordenar suas vidas.

O efeito de suas ações, no livro, é, basicamente, o abandono do velho anfiteatro, do espaço público e congregador. Ao lado disso, desaprendiam a capacidade de serem felizes, de se empolgarem e de sonhar.

Entretanto, nessa história, isso dura um ano e, depois, as pessoas conseguem recuperar, com a ajuda da garota Momo e com muita luta, o que lhes foi roubado. E no mesmo anfiteatro se encontram e fazem uma festa "tão animada como só os amigos de Momo sabiam fazer, que durou até as velhas estrelas ocuparem o céu” (p. 260).

Neste momento, nesta história que se está fazendo, ainda não é possível saber qual será o seu desfecho.

\section{BIBLIOGRAFIA}

BACHELARD, Gaston. A Poética do Espaço. Rio de Janeiro: Eldorado Tijuca, col. Quid, s/ data.

ENDE, Michael. Momo e o Senhor do Tempo. São Paulo: Martins Fontes, 1995.

FERREIRA, Aurélio Buarque de Holanda. Dicionário Aurélio. Rio de Janeiro: Nova Fronteita, 1988.

RESTANY, Pierre. O Poder da Arte de Hundertwasser: o Pintor-rei das Cinco Peles. Lisboa: Taschen, 1999.

SIMSON, O R. de M., PARK, Margareth B., FERNANDES, Renata S. Educaşão Não-formal: Cenários da Criação. Campinas: Unicamp/CMU, 2001. VIRILIO, Paul. Entrevista, mimeo., s/d. 